\title{
A case of drug-eluting beads transarterial chemoembolization for hepatocellular carcinoma
}

\author{
Qingbo Guan, Lei Song, Kuiyang Wang \\ Department of Interventional Radiology, The Second Affiliated Hospital of Dalian Medical University, Dalian 116041, China \\ Correspondence to: Qingbo Guan. Department of Interventional Radiology, The Second Affiliated Hospital of Dalian Medical University, 467 \\ Zhongshan Road, Dalian 116000, China. Email: 294756859@qq.com.
}

\begin{abstract}
The 83-year-old male was diagnosed with primary liver cancer. Magnetic resonance imaging (MRI) examination revealed a tumor in the right lobe of the liver with a maximum diameter of $42 \mathrm{~mm}$. The patient cannot tolerate surgery at an advanced age, so hepatic arterial chemoembolization was performed to prolong the patient's life. Intraoperative deb embolization was applied. At the same time, 3D-CT was used to identify the blood vessels of liver cancer and embolizes lymph node metastasis.
\end{abstract}

Keywords: Hepatocellular; carcinoma; transarterial chemoembolization; drug-eluting beads; lymph node metastasis

Submitted Jul 24, 2018. Accepted for publication Aug 04, 2018.

doi: $10.21037 /$ tcr.2018.08.12

View this article at: http://dx.doi.org/10.21037/tcr.2018.08.12

\section{Introduction}

Transcatheter arterial chemoembolizations currently recognized as one of the most common methods for non-operative treatment of liver cancer. Drug eluting beads (DEBs) have been imposed as novel drug delivering agents for TACE, which allows for higher concentrations of drugs within the target tumor and lower systemic concentrations compared with c-TACE.

\section{Case presentation}

An 83-year-old male was diagnosed with primary liver cancer. MRI examination revealed a tumor in the right lobe of the liver with a maximum diameter of $42 \mathrm{~mm}$. The patient cannot tolerate surgery at an advanced age, so hepatic arterial chemoembolization was performed to prolong the patient's life. Intraoperative deb embolization was applied. At the same time, 3D-CT was used to identify the blood vessels of liver cancer and embolizes lymph node metastasis.

\section{Operative techniques}

Described in this video is one of the hepatocellular carcinoma patients with retroperitoneal lymph node metastasis (Figure 1). The patients were given local anesthesia with $5 \mathrm{~mL}$ of $2 \%$ Lidocaine. The puncture of right common femoral artery was performed with a 5.0-Fr micro-puncture introducer set by using the Seldinger technique. The celiac trunk was catheterized with a 4.0-Fr RH catheter and the angiographies were completed (Figure 2). Then, the micro-catheter was introduced to the hepatic arteries and advanced further into segmental arteries by using selective catheterization (Figure 3). DEB was slowly injected into the feeding arteries through the catheter until the tumor-feeding branches were near stasis (Figure 4) after the CT can be found in local tumor necrosis. Lymph node arteries were found by angiography (Figure 5), then chemoembolization was performed (Figure 6).

\section{Discussion}

Transcatheter arterial chemoembolizations currently recognized as one of the most common methods for non-operative treatment of liver cancer (2). DEBs have been imposed as novel drug delivering agents for TACE, which allows for higher concentrations of drugs within the target tumor and lower systemic concentrations compared with c-TACE. Transarterial chemoembolization for hepatocellular carcinoma can control the tumor growth, but not completely cured $(3,4)$.

The use of CT is rapidly being replaced by multidetector CT to facilitate easier visualization of the anatomy using $3 \mathrm{D}$ images. 


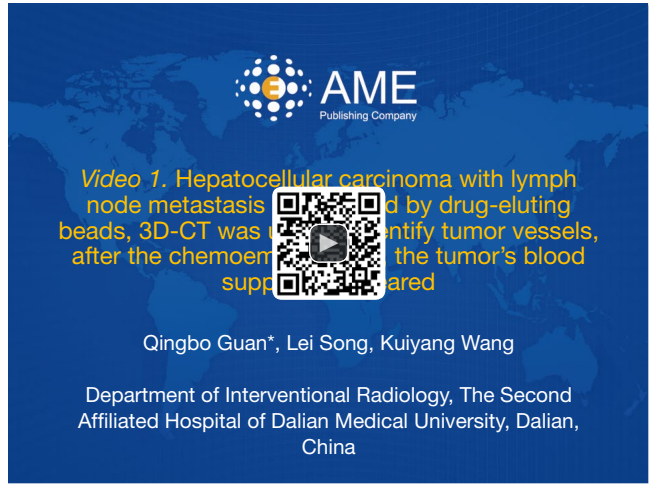

Figure 1 Hepatocellular carcinoma with lymph node metastasis was treated by drug-eluting beads, 3D-CT was used to identify tumor vessels, after the chemoembolization, the tumor's blood supply disappeared (1).

Available online: http://www.asvide.com/article/view/27100
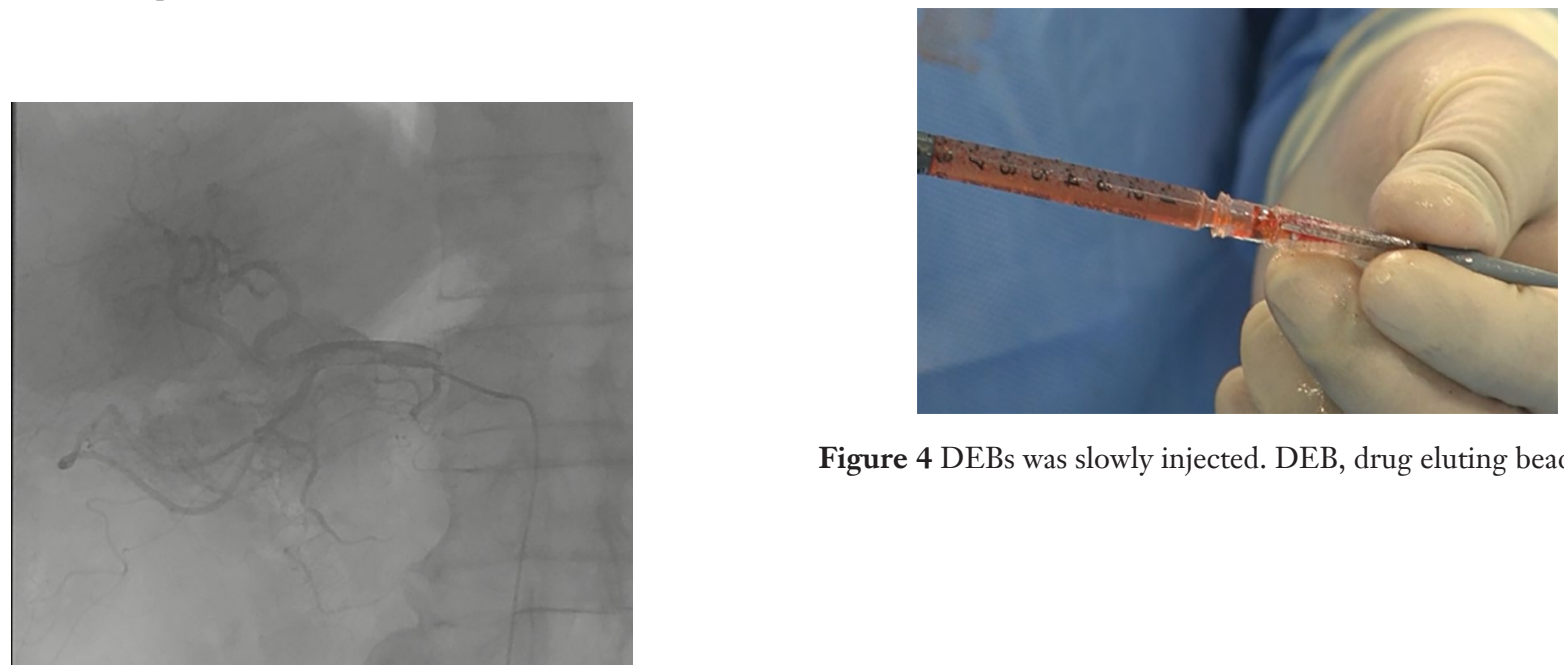

Figure 4 DEBs was slowly injected. DEB, drug eluting bead.

Figure 2 Three dimensional computed tomography (3D-CT).

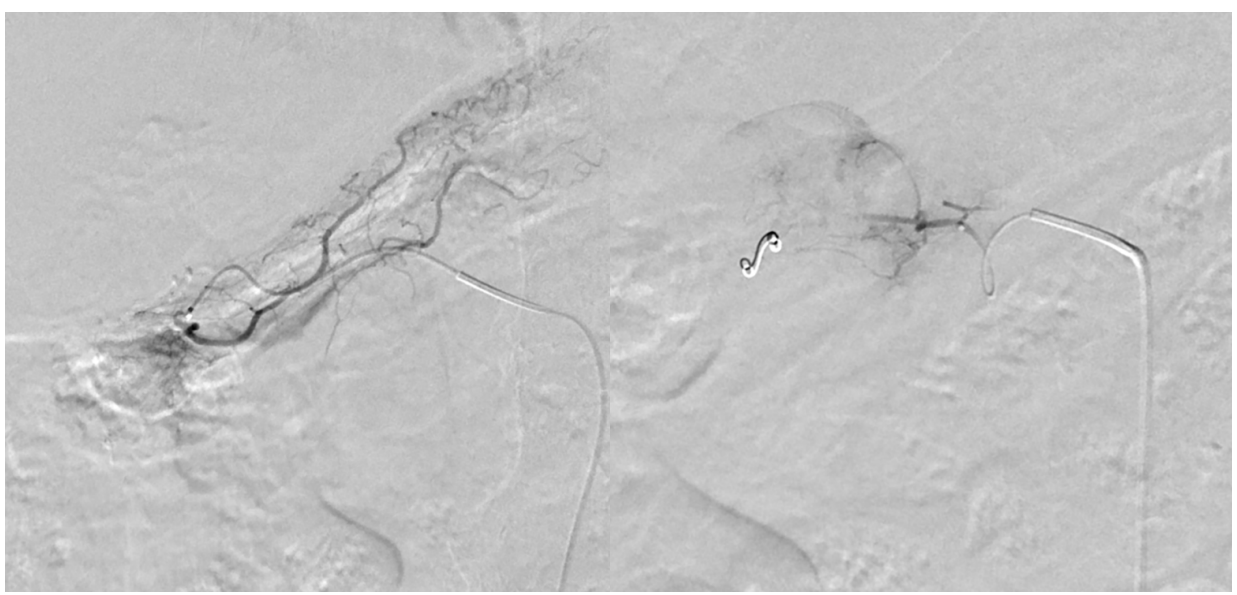

Figure 5 Lymph node angiography. 


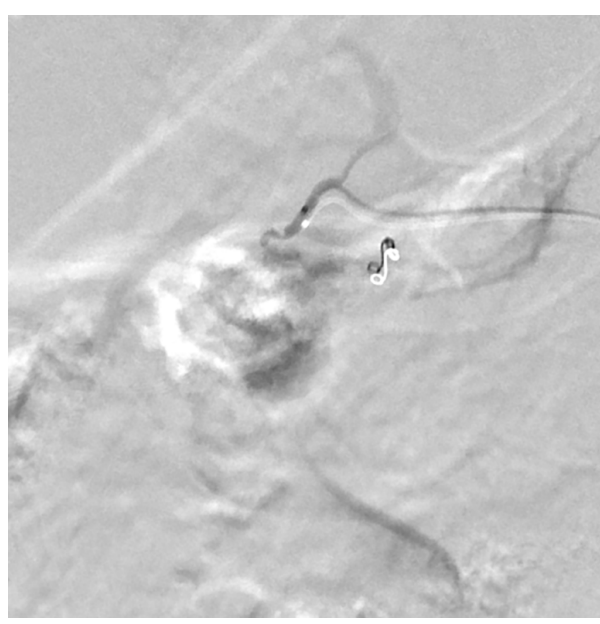

Figure 6 Spring coil guide embolization.

3DCT simulation can facilitate the precise identification of these vasculatures pre- and intra-operatively $(5,6)$.

There are limited studies to investigate TACE therapy for lymph node metastases in HCC. Therefore, little is known about its efficacy and side effects. Wu et al. verified the efficacy and safety of arterial chemoembolization for lymph node metastasis (7).

The history of this case is that elderly male hepatic artery chemoembolization prolongs the patient's life. In order to improve the accuracy of embolization, 3D-CT was used to identify tumor blood vessels. Liver cancer and lymph node metastasis were embolized respectively. False embolization may lead to pancreatitis and other complications, especially when embolization lymph node metastasis. Repeated selection of tumor vessels during surgery requires patience. Complete the operation with an artist's heart, so that better results can be achieved through intervention.

\section{Acknowledgments}

Funding: None.

\section{Footnote}

Conflicts of Interest: All authors have completed the ICMJE uniform disclosure form (available at http://dx.doi. org/10.21037/tcr.2018.08.12). The authors have no conflicts of interest to declare.

Ethical Statement: The authors are accountable for all aspects of the work in ensuring that questions related to the accuracy or integrity of any part of the work are appropriately investigated and resolved. All procedures performed in study involving human participants were in accordance with the ethical standards of the institutional and/or national research committee(s) and with the Declaration of Helsinki (as revised in 2013). Written informed consent was obtained from the patient for publication of this case report and any accompanying images.

Open Access Statement: This is an Open Access article distributed in accordance with the Creative Commons Attribution-NonCommercial-NoDerivs 4.0 International License (CC BY-NC-ND 4.0), which permits the noncommercial replication and distribution of the article with the strict proviso that no changes or edits are made and the original work is properly cited (including links to both the formal publication through the relevant DOI and the license). See: https://creativecommons.org/licenses/by-nc-nd/4.0/.

\section{References}

1. Guan Q, Song L, Wang K. Hepatocellular carcinoma with lymph node metastasis was treated by drug-eluting beads, 3D-CT was used to identify tumor vessels, after the chemoembolization, the tumor's blood supply disappeared. Asvide 2018;5:742. Available online: http://www.asvide. com/article/view/27100

2. Bureau of Medical Administration, National Health and Family Planning Comission of the People's Republic of China. Diagnosis, management, and treatment of hepatocellular carcinoma (V2017). Zhonghua Gan Zang Bing Za Zhi 2017;25:886-95.

3. Song JE, Kim DY. Conventional vs drug-eluting beads transarterial chemoembolization for hepatocellular carcinoma. World J Hepatol 2017;9:808-14.

4. Facciorusso A, Di Maso M, Muscatiello N. Drug-eluting beads versus conventional chemoembolization for the treatment of unresectable hepatocellular carcinoma: A meta-analysis. Dig Liver Dis 2016;48:571-7.

5. Oizumi H, Kanauchi N, Kato H, et al. Anatomic thoracoscopic pulmonary segmentectomy under 3-dimensional multidetector computed tomography simulation: a report of 52 consecutive cases. J Thorac Cardiovasc Surg 2011;141:678-82.

6. Kato H, Oizumi H, Inoue T, et al. Port-access thoracoscopic anatomical lung subsegmentectomy. Interact Cardiovasc Thorac Surg 2013;16:824-9.

7. Wu H, Liu S, Zheng J, et al. Transcatheter arterial chemoembolization (TACE) for lymph node metastases in patients with hepatocellular carcinoma. J Surg Oncol 2015;112:372-6.

Cite this article as: Guan Q, Song L, Wang K. A case of drug-eluting beads transarterial chemoembolization for hepatocellular carcinoma. Transl Cancer Res 2018;7(4):11721174. doi: 10.21037/tcr.2018.08.12 